\title{
Supporting Efficiency Improvement in Public Health Systems: a Rapid Systematic Review of Current Evidence
}

\author{
James Walters ${ }^{1}$, Reema Harrison ${ }^{2}$, Anurag Sharma ${ }^{2}$, and Emma Malica ${ }^{1}$ \\ ${ }^{1} \mathrm{NSW}$ Health \\ ${ }^{2}$ University of New South Wales
}

May 14, 2020

\begin{abstract}
Rationale, aims and objectives Public health systems are under pressure to meet increasing demand for health care in environments of increasing financial resource constraint. There is therefore a need to maximise health outcomes given limited public healthcare expenditure. This paper aims to establish the extent of literature and approaches to efficiency improvement in public health systems of developed countries. Methods The Rapid Evidence Assessment model was used to address the review question. Two database searches returned a result of 3,526 unique titles, which were individually screened for potential relevance. 144 titles were selected for full review to determine relevance. 73 papers were included in the final review. Results Data on country, study design, key findings and links to efficiency improvement were extracted and synthesized. Synthesis of findings revealed that the literature on this topic is disparate and non-cohesive. A range of isolated approaches were described, and no evidence or consensus on a single best-practice approach to efficiency improvement was identified. Conclusions Combining the factors identified in this review has the potential to inform a framework for supporting efficiency improvement in public health systems. By considering these factors central health system management bodies can support efficiency improvement to deliver both financial and health services benefits.
\end{abstract}

\section{Title}

Supporting Efficiency Improvement in Public Health Systems: a Rapid Systematic Review of Current Evidence

\section{Running title}

Efficiency Improvement in Public Health Systems

Author detailsAuthor 1James Walters FCHSM CHIA, A/Director, Patient Experience and System Performance Division, NSW Health, 100 Christie St, St Leonards Australia Ph: (+61) 029461 7532Author 2 Associate Professor Reema Harrison PhD, Director UNSW Health Management, School of Public Health and Community Medicine, University of New South Wales, UNSW, High St, Kensington 2052 Australia Ph: (+61) 029385 3324Author 3Dr Anurag Sharma PhD, Co-Director Public Health Programs, School of Public Health and Community Medicine, University of New South Wales, UNSW, High St, Kensington 2052 Australia Ph: (+61) 029385 2372Author 4Emma Malica FCHSM, General Manager, Program Management Office, NSW Health, 100 Christie St, St Leonards Australia Ph: (+61) 0293919000

Corresponding author name: James Walters

Corresponding author email: james.walters@health.nsw.gov.au

Corresponding author postal address: 158 Woodcourt Rd, Berowra Heights NSW 2082 Australia

Corresponding author phone: (+61) 0294617532 
1. Author's institutional affiliationsNew South Wales Health, 100 Christie St, St Leonards NSW 2065 Australia

\section{Abstract and Keywords}

Rationale, aims and objectives

Public health systems are under pressure to meet increasing demand for health care in environments of increasing financial resource constraint. There is therefore a need to maximise health outcomes given limited public healthcare expenditure. This paper aims to establish the extent of literature and approaches to efficiency improvement in public health systems of developed countries.

\section{Methods}

The Rapid Evidence Assessment model was used to address the review question. Two database searches returned a result of 3,526 unique titles, which were individually screened for potential relevance. 144 titles were selected for full review to determine relevance. 73 papers were included in the final review.

Results

Data on country, study design, key findings and links to efficiency improvement were extracted and synthesized. Synthesis of findings revealed that the literature on this topic is disparate and non-cohesive. A range of isolated approaches were described, and no evidence or consensus on a single best-practice approach to efficiency improvement was identified.

\section{Conclusions}

Combining the factors identified in this review has the potential to inform a framework for supporting efficiency improvement in public health systems. By considering these factors central health system management bodies can support efficiency improvement to deliver both financial and health services benefits.

Keywords: Public Health, Efficiency

\section{Main Text}

\section{Introduction}

Public health systems are under intense pressure to meet increasing demand for health care in environments of considerable and increasing financial resource constraint ${ }^{(1)}$. In order to continue to meet the current and future health services needs of the public there is a need to maximise health outcomes given limited public healthcare expenditure, a requirement which may also be described as efficiency improvement. Many policy suggestions to improve efficiency are based on expenditure-reducing "cost containment" initiatives, seemingly without much consideration for impacts on care quality in terms of patient outcomes and health service delivery ${ }^{(2,3)}$. We argue that such short-term, silo-based efficiency improvement approaches might not always result in improvements in patient outcomes or service delivery regardless of financial impact. We further argue that there is a need to focus on approaches that can potentially improve both efficiency and health outcomes concurrently. This paper identifies and discusses approaches to improving efficiency in public health systems which are identified as having evidence of success in enhancing both financial and health service outcomes.

Public health system efficiency and quality is challenged by factors including tightening budgets, growing demand, professional shortages, increasing disease burdens, increasing pressure on infrastructure, technological implications, changing service models and changing service accessibility ${ }^{(4)}$. An ongoing state of inefficiency amidst an environment of seemingly-constant reform is characteristic of the public health systems of many well-developed countries around the world ${ }^{(5,6)}$. Compounding this state is a common trend in rates of growth in health services demand in excess of funding growth rates, creating further pressure on already-burdened public health systems ${ }^{(7)}$. Continuing with business-as-usual approaches is likely to result in further compounding of risks to health system sustainability. The ability of public health systems to continue to meet 
these increasing pressures may not be sustainable without changes with a combined focus on efficient use of resources and service delivery optimization.

The links between care quality, care outcomes and the investments required to achieve them are wellembedded in models of health care efficiency ${ }^{(8)}$. Despite this longstanding focus, the literature on approaches to supporting efficiency and quality improvement in public health systems is disparate and non-cohesive, with a range of isolated approaches described rather than a consensus on a single best-practice approach. We suggest that there is an urgent need to consolidate understanding around efficiency improvement approaches that have been effective internationally in order to support efforts to improve health services quality and efficiency using evidence-based, best-practice approaches.

This study was undertaken in order to identify and explore what is currently known and what approaches are currently in place for supporting efficiency improvement in public health systems. There is an identified gap in the literature on this topic towards which this synthesis adds new knowledge. This paper aims to provide a consolidated view of the existing evidence to inform public health decision-making on evidencebased approaches to supporting efficiency and quality improvement. We suggest that applying the findings of this study as a framework for policy-setting and decision-making can support efficiency improvement approaches across public health systems.

\section{Purpose}

This paper aims to explore the efficiency improvement environment and approaches in public health systems using OECD countries as a frame of reference. To accomplish this aim, this paper addresses the following review question: What current evidence exists regarding approaches to supporting efficiency improvement in public health systems in developed countries? The Rapid Evidence Assessment model was used to address the review question. This model follows the same approaches and principles as a systematic review, making allowances for limited timeframes and lower strength of evidence while addressing key issues related to the topic $^{(9)}$. This method is also well-equipped to enable the synthesis of disparate evidence in addition to existing synthesised literature ${ }^{(10,11)}$. A review protocol was developed to guide this study and its processes.

\section{Data sources}

In order to limit the review to current and highly relevant material inclusion criteria were established. Only full papers available in English relating to public health systems in developed countries were included, with OECD countries used to benchmark this criterion. A timeframe for inclusion of papers published in or after 2011 was established, as this aligns with significant national health reform within the country of residence of the research team (Australia). Papers not available in English were excluded from the study, as were title matches for which full papers were not available. Papers based in developing countries were excluded in order to align with the focus of this work on OECD countries. Papers reviewed in full which held no clear content relating to efficiency improvement in public health systems were also excluded. A range of text words, synonyms and subject headings were developed for the major concepts of health system, efficiency and improvement. These search terms were used to undertake searches of two electronic databases (PUBMED, MEDLINE) in February 2019. Search results were merged with duplicates removed, and screening was managed using Covidence.

\section{Data extraction}

All titles were screened by one reviewer (JW) and potentially-relevant titles were retained. Two reviewers (JW, RH) independently screened shortlisted abstracts, with any conflicts resolved by team discussion. Full texts were obtained for these titles, and a final decision on inclusion or exclusion was made for each of these titles following full text review against the eligibility criteria. Data extracted from studies selected for inclusion were first author, publication year, country, study objective, sample, methods, key study findings and links to efficiency improvement.

\section{Results of data synthesis}


A thematic analysis of each included study was undertaken to identify key concepts related to the research question in order to inform the description of these findings through a narrative synthesis ${ }^{(12)}$. Extracted data was themed twice; firstly for major themes, and then for specific concepts relating to health services efficiency within each major theme. Regular discussions amongst the review team (JW, RH) regarding the structure, presentation and content were scheduled to guide the synthesis of extracted data. The systematic rigour and co-reviewed nature of this process grants a high degree of validity to the depth and completeness of the evidence synthesised in this review. A detailed data extraction summary table was used to document extracted data.

The two database searches returned a result of 3,526 unique titles, which were individually screened for potential relevance. 144 titles were selected for full review to determine relevance, for which full papers were obtained and reviewed. Following full-text review of these 144 papers, 73 papers were found to contain relevant material at a whole-of-system level and were included in the final review. Three major themes were identified:

1. Definitions and concepts relating to efficiency improvement

2. Central support and leadership for system-wide efficiency improvement

3. Concurrently managing efficiency, service delivery and service quality outcomes;

4. Stakeholder engagement

No evidence-based comprehensive frameworks for managing efficiency improvement in public health systems were identified.

\section{Review findings}

Financial sustainability concerns regarding public health systems in developed countries were widely acknowledged, along with the associated need for efficiency improvement to meet these concerns. Papers selected for inclusion in this review described various approaches to address these issues, however no single, best-practice or evidence-based comprehensive framework for managing these issues at the system level was identified. The findings discussed in the subsequent section of this paper outline the efficiency context, factors, considerations and approaches relevant to the review question in order to inform a framework for managing efficiency improvement that offers a range of strategies and supporting evidence. Given the fragmented and disparate nature of the evidence identified, there were no clear and consistent themes or factors which were consistently identified across all countries or health systems. Rather, the synthesis of these factors provides a collective view of factors which may be applicable to public health systems in developed countries. The thematic analysis of factors outlined below is the result of the synthesis of related but separately-identified issues with each issue being identified in only one or a few papers evaluated, rather than a wide consensus of repeated key themes identified across all papers reviewed.

\section{Definitions and concepts relating to efficiency improvement}

The concept of efficiency in the context of health services is well-explored in the literature, with clear links to expenditure, health system and health service outcomes. Productive efficiency involves making the most of available resources while maximizing outputs ${ }^{(1)}$. Multiple factors contribute to the efficiency landscape. Efficiency is comprised of technical and allocative factors within the context of existing resources, operating requirements, regulatory environments and health service outputs ${ }^{(13,4)}$. In healthcare these elements extend to the delivery of services with comprehensiveness, coordination, accessibility, quality and continuity all seen as determinants of health services efficiency ${ }^{(15)}$. In this context Pelone et al. ${ }^{(15)}$ further provided that quality involves health service effectiveness, safety and appropriateness along with patient-centeredness and patient experience. When considering processes and outcomes, the concept of technical efficiency involves achieving specified outputs using the minimum amount of resources ${ }^{(16)}$. The concept of value is also associated with efficiency in terms of weighing outcomes against the costs required to achieve them ${ }^{(17)}$.

Central support and leadership for system-wide efficiency improvement

The current public health services environment in developed countries is consistently described in the litera- 
ture in terms of increasing resource pressure and system demand, creating an increasing focus on sustainability across public health systems ${ }^{(18)}$. Specific and clear support for efficiency improvement initiatives from the system management entities of public health systems is critical to efficiency improvement success ${ }^{(19)}$. Despite this requirement, policy guidelines for enhancing public health service efficiency are not readily evident despite widespread focus on measuring efficiency ${ }^{(1)}$. Across the literature, examples of facility-level efficiency improvement projects are common however studies focusing on efficiency improvement at the system-level are rare $^{(1)}$. Variable levels of efficiency appear to be evident within any given public health system between the different services and facilities of that system ${ }^{(20)}$.

The decentralized, department-based nature of healthcare facilities within public health systems has been identified as a source of inefficiency ${ }^{(21)}$. This issue may be scalable to entire public health systems with devolved governance structures. It is noted than while reform can drive short term efficiency change, longterm sustainability requires ongoing focus and monitoring ${ }^{(22)}$. Limiting the empowerment of individual facilities to determine unique management and operating models in favour of central control is not effective in improving efficiency, which suggests that efficiency improvement can be supported through empowering facilities to tailor operating models which best fit their unique local needs while providing specific guidance on required outcomes ${ }^{(3,23)}$. This process requires consideration of public health priorities, training, policy frameworks and business models ${ }^{(24)}$. Devolution of governance from central bodies to health services can be managed through service agreements and performance measures or indicators ${ }^{(25,26)}$. Successful performance against these metrics can be supported at the system level by embedding a central focus on resource allocation in tandem with a focus on optimizing care outcomes and resource utilization, with such an approach also having the potential to avoid ethical dilemmas associated with return on investment in the context of promoting health outcomes ${ }^{(27)}$.

In systems with fixed budgets, cost savings can be absorbed in other areas of the system and therefore be masked in terms of overall financial performance. This is further complicated by initiatives which take several years to produce favorable impacts in systems with annual financial cycles ${ }^{(28,29)}$. Realistic timeframes for efficiency improvement must be considered when weighing initial investment and planned returns ${ }^{(28)}$. Establishing prompts, targets, guidelines, triggers and mandatory requirements for resource allocation consideration has been linked with successfully embedding efficiency improvement and disinvestment in routine systems and processes ${ }^{(30)}$. This can also be supported through gaining an understanding of the points where efficiencies are redistributed throughout the system ${ }^{(31)}$. It has also been suggested that focusing on productivity, savings, waste reduction and resource maximization together when managing health services can promote efficiency and quality outcomes concurrently ${ }^{(32,33)}$. Of these measures it has been suggested that productivity is less frequently used than other performance and operational efficiency measures, making productivity an area where additional insight may be generated $^{(34)}$.

Elements of transparency in target-setting and performance reporting are linked with more-efficient health organizations $^{(35)}$. The setting of system-wide financial rules has been associated with a modest reduction in public health expenditure, however this may not occur until 1-2 years following implementation ${ }^{(36)}$. Local networking and benchmarking can promote collaboration identify both high-performing and low-performing sites and is associated with higher-performing health services ${ }^{(35,37)}$. This suggests that setting realistic timeframes for improvements to be delivered and benefits realized while benchmarking to track performance are evidence-based success factors in efficiency improvement performance evaluation.

Peer benchmarking and comparison can also provide insight into new potential opportunities for efficiency improvement by identifying approaches which are achieving positive outcomes ${ }^{(38)}$. Successful initiatives can then potentially be scaled and shared to similar settings elsewhere ${ }^{(39,40)}$. This sharing of successful initiatives promotes sustainability through increasing buy-in and by building evidence of success ${ }^{(41)}$. The ability to adapt an initiative to suit local needs is a key long-term initiative success factor and a factor which also includes the ability to modify approaches over time ${ }^{(41)}$.

Identifying high-performing sites and organizations provides opportunities to identify and share factors associated with high performance ${ }^{(42)}$. Monitoring activity against set targets and requirements can enable 
success to be championed and support to be targeted as needed ${ }^{(43)}$. Allin, Grignon \& Wang ${ }^{(1)}$ suggest that peer benchmarking provides opportunities to better allocate resources and take specific actions to improve performance, as does identifying high-performing sites and organizations in order to identify and share factors associated with high performance.

Despite a focus on changes which improve efficiency the longevity of these changes appears variable, with one study suggesting that only $60 \%$ of improvement projects in health are able to maintain at least one key project element on an ongoing basis ${ }^{(44)}$. This calls for a system-wide focus on embedding key elements of successful programs upon project completion. Less-successful programs can also contribute to efficiency improvement practices, as examining reasons for failed programs can assist with supporting those at risk ${ }^{(45)}$. It is therefore recommended to identify the causes of efficiency improvement failure and take action to ensure these causes are not repeated in future efficiency improvement initiatives.

Sharing risks, goals, responsibilities and feedback across public health systems can promote a sustainable winwin outcome for patients and public health systems ${ }^{(46)}$. Health systems can utilize performance and activity data to detect opportunities for disinvestment, track progress towards targets and evaluate the impact of initiatives $^{(47,48)}$. Disinvestment and investment should be considered in parallel rather than separately ${ }^{(49)}$. Transparent, accountable systems and processes are required to coordinate these factors ${ }^{(49)}$. Improvements to services and processes must align with and embed into existing structures in order to last ${ }^{(41)}$.

It is important for public health systems to identify and overcome barriers to successfully promoting efficiency improvement. Performance measurement processes are important, however delays in reporting back from central bodies to local facilities it seen as a barrier to improvement ${ }^{(41)}$. A lack of business plans in proposed efficiency improvement processes poses a risk to achieving desired outcomes ${ }^{(50)}$. Over-restructuring, focusing on short-term goals, focusing on advances rather than results and a culture of complacency were also identified as barriers to efficiency improvement ${ }^{(51)}$. Avoiding these pitfalls should be a constant consideration at the system level.

Public health system management bodies can take a lead role in identifying low-value and high-risk procedures then removing less efficient choices, removing funding, producing policy guidelines/regulatory frameworks for cost-effective alternatives and raising the profile of correct/incorrect interventions ${ }^{(52,43)}$. The identification and scaling-up of high-value initiatives is an area of opportunity in this space ${ }^{(53)}$. Evidence for cost savings in similar initiatives in other health jurisdictions can be used to justify investment decisions and develop business cases for efficiency improvement initiatives ${ }^{(54)}$. Centralizing and consolidating services can enhance performance, as can centrally-set, system-wide annual efficiency targets ${ }^{(55)}$. Evidence is mixed for extending this approach to public-private partnerships, which have been described as complex, difficult to implement and dependant up a range of pre-existing conditions to succeed ${ }^{(56,57)}$. Pay-for-quality schemes and mergers between public hospitals intended to improve performance are similarly fraught with limited evidence for efficiency and quality improvement ${ }^{(2,58)}$.

Centralized efficiency improvement units such as Program Management Offices can have an impact on improving efficiency across public health systems by providing support and reducing pressure on health service managers ${ }^{(59)}$. The extent to which the support offered by such units is adopted can be significantly dependent upon the engagement and enthusiasm of senior leadership across their public health system ${ }^{(4)}$. The decision-making level of the efficiency improvement unit has significant bearing on the efficiency improvement focus and activities of the unit ${ }^{(1)}$. Program Management Offices in health care promote efficiency as they can help solve operations issues, reduce spending, share expertise, standardize practices/processes, build capability, provide regular progress reporting, promote effective communication, assist various stakeholder groups to deliver results, optimize processes, evaluate impacts and align management approaches to client satisfaction $^{(59)}$.

In order to realize the potential benefits offered by centralized efficiency improvement units, challenges were identified which require consideration. These include task prioritization, managing expectations and managing multiple concurrent projects ${ }^{(59)}$. The manner in which the capabilities and system knowledge of 
these teams is perceived by stakeholders impacted by efficiency improvement-related change is a determinant of the degree to which improvement initiatives are adopted across public health systems ${ }^{(4)}$. This suggests that appointing team members recognized for their experience, credibility and familiarity with the public health system involved will facilitate the team's ability to deliver efficiency improvement support. Establishing and managing realistic expectations as to the service offerings of such teams across their stakeholders has also been associated with the effectiveness of efficiency improvement support ${ }^{(59)}$.

\section{Concurrently managing efficiency, service delivery and service quality outcomes}

An emerging focus on concurrently improving both quality and efficiency is replacing the previous focus on purely financial efficiency, with evidence suggesting that focusing solely on financial efficiency does not result in health service efficiency improvements ${ }^{(3)}$. At a system level the factors contributing to efficiency improvement include focusing on efficiency at all facilities and organizational levels, addressing unwarranted variation, considered use of funding levers, and monitoring appropriate performance indicators ${ }^{(16)}$. Public health systems have a role in shaping policy to encourage services which promote both efficiency and better stakeholder outcomes ${ }^{(60)}$. Underpinning any efficiency improvement initiative are concurrent requirements to improve patient satisfaction, service quality and staff engagement in addition to managing cost ${ }^{(60)}$. Gerald ${ }^{(61)}$ suggests that this can be successfully approached through setting policy levers which prioritize affordability, access to care and innovation rather than targeting price or utilization-based metrics as priority outcomes.

Efficiency improvement can be addressed in alignment with patient outcomes and service quality, although inefficiency cannot be rectified simply through additional resourcing ${ }^{(5)}$. Efficiency gains can be realized in combination between quality and patient outcomes, with quality, cost and productivity regarded as interlinked rather than isolated ${ }^{(39,62)}$. Addressing health services overuse and low-value activities is also linked to both effectiveness and efficiency ${ }^{(63)}$. While technological solutions can potentially enhance efficiency across a broad range of areas their potential is frequently overrated, with developing and implementing such solutions being a driver of $\operatorname{cost}^{(64,65)}$. Importantly, health services cannot be expected to operate at near-maximum efficiency levels as consideration to reduced efficiency is a trade-off for workforce training capacity, research and innovation ${ }^{(66)}$. This calls for the setting of realistic and balanced efficiency improvement targets and timeframes. It has also been suggested that effective training in the actions required to deliver efficiency improvement, consistent leadership and continued post-implementation monitoring are required in order for improvements in efficiency to be maintained ${ }^{(4)}$.

\section{Stakeholder engagement}

Underpinning any efficiency improvement initiative are concurrent requirements to improve patient satisfaction, service quality and staff engagement in addition to managing $\operatorname{cost}^{(60)}$. Despite the clear need to enhance efficiency, overcoming the challenges of staff resistance and staff expectations can prove difficult. Common misconceptions amongst staff and patients that "more is better" and "newer is better" are a significant barrier ${ }^{(63)}$. There is a risk for resource investment to be considered a waste if no value is added to patient outcomes ${ }^{(46)}$. To mitigate this risk, the involvement of stakeholders in target-setting has been associated with improved acceptance and compliance towards established targets ${ }^{(67)}$. Clear target definition and stakeholder collaboration during improvement initiative development are factors for improvement initiative success ${ }^{68,69)}$. Collaboration, knowledge sharing, performance monitoring and continuous training in performance improvement are associated with project sustainability and impact ${ }^{(4)}$. It was clear throughout the studies reviewed that effective, ongoing consultation and collaboration is a core element in efficiency improvement.

To counter stakeholder engagement challenges, public health systems can focus on enhancing collaboration and engagement to promote efficiency improvement ${ }^{(46)}$. Stakeholders are unlikely to be motivated to engage in efficiency improvement solely because of cost-effectiveness ${ }^{(70)}$. Local management priorities can be aligned across the system by linking unit manager goals, measures and incentives to those of the Organization, thereby promoting efficiencies at a system level and moving away from isolated pockets of improvement ${ }^{(71)}$. Central bodies can sponsor collaborative networks to share successful practice and performance informa- 
tion, with links to improved patient outcomes and costs while also linking researchers with implementers and beneficiaries ${ }^{(72)}$. Consideration towards the issues of data security and systems interoperability is required when planning technological solutions to support collaboration, information sharing and performance management ${ }^{(73)}$. Although change management approaches were not the focus of this review, the evidence identified in this study consistently indicated that effective change management is required in any efficiency improvement initiative.

\section{Discussion}

This review has identified that the current body of research is not cohesive and does not provide evidence of single, comprehensive approaches to supporting efficiency improvement in public health systems. Many individual aspects and factors were identified from across the sources reviewed in this paper which relate to improving health services efficiency, and together these factors may inform the design of a comprehensive support framework. The critical need to allow flexibility to align any improvement initiatives with existing local processes and individual service needs may also be supported by such an approach ${ }^{(3)}$. Service integration, collaboration, benchmarking, locally-tailored solutions and knowledge sharing were clear themes in successful approaches to supporting efficiency improvement ${ }^{(35,38,41)}$.

A range of challenges to achieving efficiency improvement across public health systems were identified. This review identified a lack of clarity in the literature around an evidence-based best-practice approach to managing efficiency improvement at a whole-of-system level. Continuous restructuring, delays in performance reporting, the setting of short-term reactive goals and the prioritization of cost reduction over service enhancement are barriers to efficiency improvement ${ }^{(74)}$. The historical design of health systems based around siloes and episodes of care also presents a barrier to be overcome ${ }^{(75)}$. Despite the interlinked nature of financial performance and health services outcomes, these outcomes are not always addressed concurrently ${ }^{(60)}$. Capability, enthusiasm and centrally-led support for efficiency-focused initiatives across public health systems is not always sufficient to enable sustained improvements ${ }^{(4)}$. Health services should be aware of the impact of measures which may appear to represent efficiency on paper but which do not represent genuine efficiency such as efforts to increase coding acuity, coding creep and selective picking of more highly-valued $\operatorname{activity}^{(76,77)}$. Caution should also be applied to delaying essential activity and expenditure to represent short-term financial improvements as this can be detrimental to service quality, accessibility and stability ${ }^{(78)}$.

The impact of policy in establishing conditions for health services to manage efficiency was evident. Transparent target setting and progress reporting processes for efficiency improvement were supported, while pairing financial improvement initiatives with efficiency improvement and strategic directions was a key policy consideration which can support efficiency improvement ${ }^{(16,61)}$. Effective Organization-wide stakeholder engagement and consultation is linked with successful change at the public health system level ${ }^{(69)}$. There is clear scope for support for efficiency improvement to be provided across healthcare facilities and districts by the managing bodies of public health systems, such as Ministries and Departments of Health ${ }^{(27)}$. Dedicated efficiency improvement offices or teams at appropriate decision-making levels within these system management bodies can enable knowledge sharing, enhance engagement with efficiency improvement and coordinate system-wide efficiency improvement programs ${ }^{(4,1)}$. The Program Management Office model is an evidence-based approach to providing this support across public health systems ${ }^{(59)}$.

\section{Implications and application}

The current public health system climate is one of increasing demand and tightening resourcing, yet the vast majority of project-level sustainability approaches in healthcare do not include a cost-related definition of sustainability ${ }^{(44)}$. System-level responses to the challenge presented by the increasing need for efficiency are often reactive, involving short-term actions such as reducing funding rates, setting short-term targets, reducing services and delaying non-essential activities ${ }^{(74)}$. Such approaches are unlikely to result in sustainable improvements and are also likely to impact capacity for investment, capability development and innovation aimed at improving both quality and efficiency ${ }^{(79)}$. Continuing with such approaches is unlikely to meet current and future sustainability pressures ${ }^{(7)}$. 
This study presents a synthesized view of current evidence relevant to efficiency improvement in public health systems. While studies aimed at improving efficiency were widespread, no single comprehensive frameworks were identified in this review. This paper addresses the gap in the literature in this space by outlining the range of current evidence-based factors and strategies associated with supporting efficiency improvement in public health systems. Evidence is also presented which supports tandem improvements in financial efficiency and health service outcomes. Public health systems in developed countries may find guidance in this study on which efficiency improvement approaches are linked with success. The findings of this study may also be used to guide reflection on current practice in order to identify approaches in place as well as potentially-successful approaches not currently in place for the purpose of validating and augmenting efficiency improvement practices.

\section{Limitations}

By searching only two databases in this study, the possibility that published work relevant to the review question may have been overlooked cannot be excluded. Similarly, by focusing only on published peerreviewed works, relevant perspectives in other works may also have been excluded. While the search terms selected were broad and relevant, given the diverse and far-reaching nature of the topic it is possible that relevant material may have been missed where this material was described using different key terms than those selected for this study.

\section{Conclusion}

The requirement for efficiency in the delivery of public health services continues to increase. This narrative synthesis presents a combined view of factors identified in the literature related to efficiency improvement in public health systems. We argue that addressing the challenges and enabling actions identified in this study represents an evidence-based approach to supporting efficiency improvement. Combining these factors can inform a framework for supporting efficiency improvement in public health systems. By addressing each of these factors as appropriate to specific local needs and by providing system-wide support for efficiency improvement, central health system management bodies can promote efficiency improvement in parallel with patient, staff and service quality outcomes.

\section{References}

1. Allin S, Grignon M, Wang L. The determinants of efficiency in the Canadian health care system. Health Econ Policy Law 2016;11:39-65.

2. Jeurissen P, Duran A, Saltman RB. Uncomfortable realities: the challenge of creating real change in Europe's consolidating hospital sector. BMC Health Serv Res 2016;16:168.

3. Zhang X, Tone K, Lu Y. Impact of the Local Public Hospital Reform on the Efficiency of Medium-Sized Hospitals in Japan: an Improved Slacks-Based Measure Data Envelopment Analysis Approach. Health Serv Res 2018;53:896-918.

4. Hassanain M. An overview of the performance improvement initiatives by the ministry of Health in the Kingdom of Saudi Arabia. Inquiry 2017;54:1-6.

5. Akinci F, Patel PM. Quality improvement in healthcare delivery utilizing the patient-centered medical home model. Hosp Top 2014;92:96-104.

6. Mateus C, Joaquim I, Nunes C. Measuring hospital efficiency - comparing four European countries. Eur J Public Health 2015;25;52-58.

7. Blank JL, Eggink E. The impact of policy on hospital productivity: a time series analysis of Dutch hospitals. Health Care Manag Sci 2014;17:139-149.

8. Donabedian A, Wheeler JRC, Wyszewianski, L. Quality, cost, and health: an integrative model. Med Care 1982;20;975-992.

9. Grant MJ, Booth A. A typology of reviews: an analysis of 14 review types and associated methodologies. Health Info Libr J 2009;26:91-108.

10. Hiscock H, Perera P, Mclean K, Roberts G, Lucas G, Kelly M, Klineberg E, White L. Variation in paediatric clinical practice: a review of care in inpatient, outpatient and emergency department 
settings. J Paediatr Child Health 2016;52:691-3.

11. Moher D, Liberati A, Tetzlaff J, Altman DG. Preferred reporting items for systematic reviews and meta-analyses: the PRISMA statement. Ann Int Med 2009;151:264-269.

12. Popay J, Roberts H, Sowden A, Petticrew M, Arai L, Rodgers M, Britten N, Roen K, Duffy S. Guidance on the conduct of narrative synthesis in systematic reviews: a product from the ESRC methods programme. Lancaster: Lancaster University 2006 Apr;10:1018-4643

13. Harrison JP, Kirkpatrick N. The improving efficiency frontier of inpatient rehabilitation hospitals. Health Care Manag 2011;30:313-321.

14. Tchouaket ÉN, Lamarche PA, Goulet L, Contandriopoulos AP. Health care system performance of 27 OECD countries. Int J Health Plann Manag 2012;27:104-129.

15. Pelone F, Kringos DS, Spreeuwenberg P, De Belvis AG, Groenewegen PP. How to achieve optimal organization of primary care service delivery at system level: lessons from Europe. Int J Qual Health C 2013;25:381-393.

16. Rumbold BE, Smith JA, Hurst J, Charlesworth A, Clarke A. Improving productive efficiency in hospitals: findings from a review of the international evidence. Health Econ Policy Law 2015;10:21-43.

17. Chen KK, Harty JH, Bosco JA. It is a brave new world: alternative payment models and value creation in total joint arthroplasty: creating value for TJR, quality and cost-effectiveness programs. J Arthroplasty 2017;32:1717-1719.

18. Pencheon D. Making health care more sustainable: the case of the English NHS. Public Health 2015;129:1335-1343.

19. Fiorentini G, Iezzi E, Bruni ML, Ugolini C. Incentives in primary care and their impact on potentially avoidable hospital admissions. Eur J Health Econ 2011;12:297-309.

20. Allin S, Veillard J, Wang L, Grignon M. How can health system efficiency be improved in Canada? Healthc Policy 2015;11:33.

21. Zhivan NA, Diana ML. US hospital efficiency and adoption of health information technology. Health Care Manag Sci 2012;15:37-47.

22. Mitropoulos P, Mitropoulos I, Karanikas H, Polyzos N. The impact of economic crisis on the Greek hospitals' productivity. Int J Health Plann Manag 2018;33:171-184.

23. Ovseiko PV, O'Sullivan C, Powell SC, Davies SM, Buchan AM. Implementation of collaborative governance in cross-sector innovation and education networks: evidence from the National Health Service in England. BMC Health Serv Res 2014:14;552.

24. Strand MA, Davidson KM, Schulze N. Linking pharmacists to the delivery of public health services. J Am Pharm Assoc 2017;57:742-746.

25. Anderson T, Catchlove B. Health and hospital reform in Australia - a local health district's perspective. World Hosp Health Serv 2012;48:21.

26. Saunders C, \& Carter DJ. Is health systems integration being advanced through Local Health District planning? Aust Health Rev 2017;41:154-161.

27. Harris C, Green S, Ramsey W, Allen K, King R. Sustainability in Health care by Allocating Resources Effectively (SHARE) 9: conceptualising disinvestment in the local healthcare setting. BMC Health Serv Res 2017;17:633.

28. Hebert PL, Liu CF, Wong ES, Hernandez SE, Batten A, Lo S, Lemon JM, Conrad DA, Grembowski D, Nelson K, Fihn SD. Patient-centered medical home initiative produced modest economic results for Veterans Health Administration, 2010-12. Health Aff 2014;33:980-987.

29. Pettersen IJ, Solstad E. Vertical and horizontal control dilemmas in public hospitals. J Health Organ Manag 2015;29:185-199.

30. Harris C, Green S, Elshaug AG. Sustainability in Health care by Allocating Resources Effectively (SHARE) 10: operationalising disinvestment in a conceptual framework for resource allocation. BMC Health Serv Res 2017;17:632.

31. Bradford NK, Caffery LJ, Smith AC. Telehealth services in rural and remote Australia: a systematic review of models of care and factors influencing success and sustainability. Rural Remote Health $2016 ; 16: 3808$. 
32. Ashton T, Bramley D, Armstrong D. Improving the productivity of elective surgery through a new 'package of care'. Health Policy 2012;108:45-48.

33. Harris C, Green S, Ramsey W, Allen K, King, R. Sustainability in Health care by Allocating Resources Effectively (SHARE) 1: Introducing a series of papers reporting an investigation of disinvestment in a local healthcare setting. BMC Health Serv Res 2017;323.

34. Tsai MH, Huynh TT, Breidenstein MW, O'Donnell SE, Ehrenfeld JM, Urman RD. A system-wide approach to physician efficiency and utilization rates for non-operating room anesthesia sites. J Med Syst 2017;41:112.

35. Nuti S, Vola F, Bonini A, Vainieri M. Making governance work in the health care sector: evidence from a 'natural experiment' in Italy. Health Econ Policy Law 2016;11:17-38.

36. Schakel HC, Wu EH, Jeurissen P. Fiscal rules, powerful levers for controlling the health budget? evidence from 32 OECD countries. BMC Public Health 2018;18:300.

37. Uddin S, Hossain L, Kelaher M. Effect of physician collaboration network on hospitalization cost and readmission rate. European J Public Health 2011;22:629-633.

38. White C. Stronger grip on overheads and increased productivity could save NHS hospitals £5bn a year. Br Med J 2015;350:h3228

39. Cullen J, Bramley D, Armstrong D, Butler L, Rouse P, Ashton T. Increasing productivity, reducing cost and improving quality in elective surgery in New Zealand: the Waitemata District Health Board joint arthroplasty pilot. Intern Med J 2012;42:620-626.

40. Grimes KE, Schulz MF, Cohen SA, Mullin BO, Lehar SE, Tien S. Pursuing cost-effectiveness in mental health service delivery for youth with complex needs. J Ment Health Policy Econ 2011;14:73.

41. Ament SM, Gillissen F, Moser A, Maessen JM, Dirksen CD, von Meyenfeldt, MF, van der Weijden T. Factors associated with sustainability of 2 quality improvement programs after achieving early implementation success. a qualitative case study. J Eval Clin Pract 2017;23:1135-1143.

42. Abraham C, Nishihara E, Akiyama M. Transforming healthcare with information technology in Japan: a review of policy, people, and progress. Int J Med Inform 2011;80:157-170.

43. García-Armesto S, Campillo-Artero C, Bernal-Delgado E. Disinvestment in the age of cost-cutting sound and fury. tools for the Spanish National Health System. Health Policy 2013;110:180-185.

44. Lennox L, Maher L, Reed J. Navigating the sustainability landscape: a systematic review of sustainability approaches in healthcare. Implement Sci 2018;13:27.

45. SteelFisher GK, Martin LA, Dowal SL, Inouye SK. Learning from the closure of clinical programs: a case series from the hospital elder life program. J Am Geriatr Soc 2013;61:999-1004.

46. De Rosis S, Nuti S. Public strategies for improving eHealth integration and long-term sustainability in public health care systems: findings from an Italian case study. Int J Health Plann Manag 2018;33:e131e152.

47. Harris C, Allen K, Waller C, Dyer T, Brooke V, Garrubba M, Melder A, Voutier C, Gust A, Farjou D. Sustainability in Health care by Allocating Resources Effectively (SHARE) 7: supporting staff in evidence-based decision-making, implementation and evaluation in a local healthcare setting. BMC Health Serv Res 2017;17:430.

48. Vest JR, Kash BA. Differing strategies to meet information-sharing needs: publicly supported community health information exchanges versus health systems' enterprise health information exchanges. Milbank Q 2016;94:77-108.

49. Harris C, Allen K, Waller C, Green S, King R, Ramsey W, Kelley C, Thiagarajan M. Sustainability in Health care by Allocating Resources Effectively (SHARE) 5: developing a model for evidence-driven resource allocation in a local healthcare setting. BMC Health Serv Res 2017;17:342.

50. Adler-Milstein J, Bates DW, Jha AK. Operational health information exchanges show substantial growth, but long-term funding remains a concern. Health Aff 2013;32:1486-1492.

51. Bosch X, Moreno P, Lopez-Soto A. The painful effects of the financial crisis on Spanish health care. Int J Health Serv 2014;44:25-51.

52. Barnett ML, Yee Jr HF, Mehrotra A, Giboney P. Los Angeles safety-net program eConsult system was rapidly adopted and decreased wait times to see specialists. Health Aff 2017;36:492-499. 
53. Elshaug AG, Rosenthal MB, Lavis JN, Brownlee S, Schmidt H, Nagpal S, Littlejohns P, Srivastava D, Tunis S, SainiV. Levers for addressing medical underuse and overuse: achieving high-value health care. Lancet 2017;390:191-202.

54. Gaertner J, Maier BO, Radbruch L. Resource allocation issues concerning early palliative care. Ann Palliat Med 2015;4:156-161.

55. Christiansen T, Vrangbaek K. Hospital centralization and performance in Denmark-Ten years on. Health Policy 2018;122:321-328.

56. Braithwaite J, Travaglia JF, Corbett A. Can questions of the privatization and corporatization, and the autonomy and accountability of public hospitals, ever be resolved? Health Care Anal 2011;19:133-153.

57. Longo MC. Good Practices in Health Care "Management Experimentation Models": insights from an International Public-Private Partnership on Transplantation and Advanced Specialized Therapies. Adv Health Care Manag 2015;17:71-115.

58. Gaynor M, Laudicella M, Propper C. Can governments do it better? merger mania and hospital outcomes in the English NHS. J Health Econ 2012;31:528-543.

59. Lavoie-Tremblay M, Bonneville-Roussy A, Richer MC, Aubry M, Vezina M, Deme M. Project management office in health care: a key strategy to support evidence-based practice change. Health Care Manag 2012;31:154-165

60. Gans D, Kominski GF, Roby DH, Diamant AL, Chen X, Lin W, Hohe N. Better outcomes, lower costs: palliative care program reduces stress, costs of care for children with life-threatening conditions. Policy brief (UCLA Center for Health Policy Research) 2012;PB2012-3;1-8.

61. Gerald JK. Ten principles to guide health reform. Ann A Thorac Soc 2017;14:420-425.

62. Kumar S, Ghildayal NS, Shah, RN. Examining quality and efficiency of the US healthcare system. Int J Health Care Qual Assur 2011;24:366-388.

63. Ellen ME, Wilson MG, Velez M, Shach R, Lavis JN, Grimshaw JM, Moat KA. Addressing overuse of health services in health systems: a critical interpretive synthesis. Health Res Policy Syst 2018;16:48.

64. Anstey MHR, Elshaug AG, Russell LM, Wells S. Can we learn anything from health care in the United States? Med J Aust 2014;200:526-528.

65. Birch S, Murphy GT, MacKenzie A, Cumming J. In place of fear: aligning health care planning with system objectives to achieve financial sustainability. J Health Serv Res Policy 2015;20:109-114.

66. Stimpson JP, Li T, Shiyanbola OO, Jacobson JJ. Financial sustainability of academic health centers: identifying challenges and strategic responses. Acad Med 2014;89:853-857.

67. Kearney LK, Smith C, Kivlahan, DR, Gresen RC, Moran E, Schohn M, Trafton J, Zeiss AM. Mental health productivity monitoring in the Veterans Health Administration: challenges and lessons learned. Psychol Serv 2018;15:486.

68. Murphy DJ, Lyu PF, Gregg SR, Martin GS, Hockenberry JM, Coopersmith CM, Sterling M, Buchman TG, Sevransky, J. Using incentives to improve resource utilization: a quasi-experimental evaluation of an ICU quality improvement program. Crit Care Med 2016;44:162.

69. Harris C, Ko H, Waller C, Sloss P, Williams P. Sustainability in Health care by Allocating Resources Effectively (SHARE) 4: exploring opportunities and methods for consumer engagement in resource allocation in a local healthcare setting. BMC Health Serv Res 2017;17:329.

70. Robertson J, Walkom EJ, Henry DA. Health systems and sustainability: doctors and consumers differ on threats and solutions. PLoS One 2011;6;e19222.

71. Kamarainen VJ, Peltokorpi A, Torkki P, Tallbacka K. Measuring healthcare productivity-from unit to system level. Int J Health Care Qual Assur 2016;29:288-299.

72. Auerbach AD, Patel MS, Metlay J, Schnipper J, Williams MV, Robinson E, Kripalani S, Lindenauer PK. The Hospital Medicine Reengineering Network (HOMERuN): a learning organization focused on improving hospital care. Acad Med 2014;89:415

73. Walker DM. Does participation in health information exchange improve hospital efficiency? Health Care Manag Sci 2018;21:426-438.

74. Bosch X, Moreno P, Lopez-Soto A. The painful effects of the financial crisis on Spanish health care. Int J Health Serv 2014;44:25-51 
75. Breen C, Altman L, Ging J, Deverell M, Woolfenden S, Zurynski Y. Significant reductions in tertiary hospital encounters and less travel for families after implementation of Paediatric Care Coordination in Australia. BMC Health Serv Res 2018;18:751.

76. Himmelstein DU, Jun M, Busse R, Chevreul K, Geissler A, Jeurissen P, Thomson S, Vinet MA, Woolhandler, S. A comparison of hospital administrative costs in eight nations: US costs exceed all others by far. Health Affairs 2014;33:1586-1594.

77. Mancuso P, Valdmanis VG (2016). Care appropriateness and health productivity evolution: a nonparametric analysis of the Italian regional health systems. Appl Health Econ Hea 2016;14:595-607.

78. Tataw DB. Health Policy Making Through Operative Actions: a Case Study of Provider Capacity Reduction in a Public Safety-Net System. Soc Work Public Health 2014;29:54-72.

79. Mussap M. An alternative perspective on how laboratory medicine can contribute to solve the health care crisis: a model to save costs by acquiring excellence in diagnostic systems. Clin Chim Acta2014;427:202-204.

\section{Acknowledgements}

This research did not receive any specific funding

\section{Conflict of interest}

The authors declare no conflicts of interest 